NASA Technical Memorandum 100200

AIAA-87-2719

\title{
Advanced Turboprop Wing Installation Effects Measured by Unsteady Blade Pressure and Noise
}

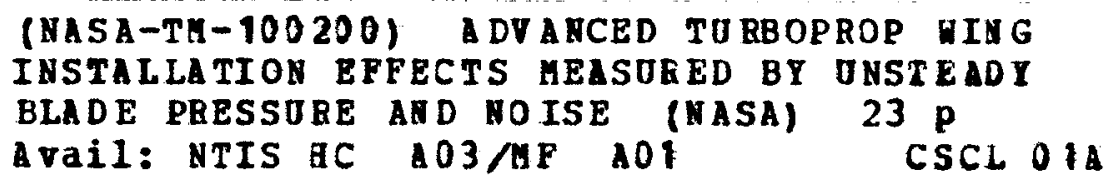

Laurence J. Heidelberg and Richard P. Woodward

Lewis Research Center

Cleveland, Ohio

Prepared for the

11th Aeroacoustics Conference

sponsored by the American Institute of Aeronautics and Astronautics

Sunnyvale, California, October 19-21, 1987 
ADVANCED TURBOPROP WING INSTALLATION EFFECTS MEASURED BY UNSTEADY BLADE PRESSURE AND NOISE

\author{
Laurence J. Heidelberg and Richard P. Woodward \\ National Aeronautics and Space Administration \\ Lewis Research Center \\ Cleveland, Ohio 44135
}

\title{
SUMMARY
}

A single rotation model propeller (SR-7A) was tested at simulated takeoff/approach conditions (0.2 Mach) in the NASA Lewis 9- by 15-Ft Anechoic Wind Tunnel. Both unsteady blade surface pressures and noise measurements were made for a tractor configuration with a propeller/straight wing and propeller alone configurations. The angle between the wing chord and propeller axis (droop angle) was varied along with the wing angle of attack to determine the effects on noise and unsteady loading. A method was developed that uses unsteady blade pressure measurements to provide a quantitative indication of propeller inflow conditions, at lease for a uniform (across the propeller disk) inflow angle. The wing installation caused a nearly uniform upwash at the propeller inlet as evidenced by the domination of the pressure spectra by the first shaft order. This inflow angle increased at a rate of almost 150 percent of that of the wing angle-of-attack for a propeller-wing spacing of 0.54 wing chords at a constant droop angle. The flyover noise, as measured by the maximum blade passing frequency level, correlates closely with the propeller inflow angle ( $0.6 \mathrm{~dB}$ per degree of inflow angle) for all droop angles and wing angles-of-attack tested, including the propeller alone data. Large changes in the unsteady pressure responses on the suction surface of the blade were observed as the advance ratio was varied. The presence of a leading edge vortex may explain this behavior since changes in the location of this vortex would change with loading (advance ratio).

\section{INTRODUCTION}

The next generation of commercial airliners is likely to be powered by an advanced turboprop that offers the promise of considerable fuel savings while still allowing for a cruise speed similar to that of current turbofan aircraft (refs. 1 and 2). However, there is considerable concern about the potential noise generated by such aircraft, which includes both in-flight cabin noise and community noise during takeoff and landing. This noise may be affected by propeller inflow conditions including installation effects such as propeller axis angle of attack and interactions between a wing flow field and the propeller.

In this investigation the propeller inflow conditions caused by a wing installation were determined from measurements of the unsteady blade surface pressures. This was done by calibrating each measuring station in terms of propeller inflow angle (propeller alone configuration) and then using this calibration to determine the unknown inflow conditions of the wing installation. The inflow conditions in terms of local inflow angle at the propeller face were then correlated to the flyover noise. This paper presents blade surface pressure and acoustic results for the SR-7A scale model of the "Large-scale Advanced Propfan" (LAP) propeller. The SR-7A propeller was tested in the NASA 
Lewis 9- by 15-Ft Anechoic Wind Tunnel. All tests were performed at a tunnel Mach of 0.2 , which is representative of the aircraft takeoff/approach speed. These tests were in support of the "Propfan Test Assessment" (PTA) f1ight program which involve tests of the full-scale LAP propeller on a modified Gulfstream II aircraft (refs. 3 and 4 ). The PTA flight tests include a variation of nacelle tilt angle from $3^{\circ}$ down to $2^{\circ}$ up.

Results are presented in this paper for the SR-7A propeller alone and for the SR-7A in a tractor installation with a straight wing. The complete acoustic results for these and several other configurations are reported in reference 5 .

\section{NOMENCLATURE}

C blade chord, $m$

$C_{p l}$ unsteady pressure coefficient for the first shaft order, $p_{1} / q_{r}$

$\mathrm{J}$ advance ratio, $v_{\infty} / 2 n R$

Mr blade relative Mach number at radius $r$

$M_{\infty} \quad$ tunnel or fight Mach number

n rotational speed, rps

$\mathrm{P}_{1}$ magnitude of the rms pressure at the first shaft order, $\mathrm{Pa}$

p static pressure, $\mathrm{Pa}$

qr local dynamic pressure at radius $r, 0.7 \mathrm{pMr}^{2}$ (for air), $\mathrm{Pa}$

$R \quad$ blade radius at tip, $m$

$r$ blade radial station, $m$

$V_{\infty} \quad$ tunnel or flight velocity, $\mathrm{m} / \mathrm{sec}$

$\alpha_{L} \quad$ local inflow angle relative to propeller axis (fig. 3 ), deg

$\alpha_{p}$ angle propeller axis makes with tunnel flow (no wing), deg

$\alpha_{w} \quad$ angle of attack of wing, deg

$\Delta / \alpha_{B}$ periodic change in blade angle of attack, deg

$\delta \quad$ droop angle, angle wing chord makes with propeller axis, negative when propeller is pitched down, deg

$\Psi \quad$ blade azmuthal angle (fig. 2) 


\section{APPARATUS AND PROCEDURE}

The NASA Lewis 9- by 15-Ft Anechoic Wind Tunnel is located in the lowspeed return loop of the 8- by 6-Ft Supersonic Wind Tunnel. The maximum airflow velocity is slightly over $0.2 \mathrm{Mach}$, which provides a takeoff/approach test environment. The tunnel acoustic treatment was modified prior to the SR-7A tests to provide anechoic conditions down to a frequency of $250 \mathrm{~Hz}$, which is lower than the range of the fundamental tone produced by the SR-7A propeller.

Figure 1 is a photograph of the SR-7A propeller installed in the 9- by 15-ft tunnel. The acoustic instrumentation is clearly seen in this picture. The SR-7A propeller was powered by an air turbine drive system. The support structure for the propeller extended between the tunnel floor and ceiling, as shown in figure 1. This structure was mounted on a turntable to provide remote positioning of the propeller axis to angle of attack in the horizontal plane. Figure 2 is a plan view of the propeller installation in the 9- by 15-ft tunnel. The propeller rotated in a clockwise direction looking downstream, and a positive angle of attack corresponds to the propeller axis angled toward the near wall.

A complete description of the acoustic instrumentation can be found in reference 5. Only the translating probe microphone data, which measures flyover noise, was used in this paper.

The SR-7A propeller is an aeroelastic scale model of the SR-7L propeller which is flying on a modified Gulfstream II test aircraft. Crulse design parameters for this propeller are presented in table I. The data presented in this paper are for the takeoff/approach condition at 0.2 Mach number. "Design" values used at this airspeed were a blade angle of $37.8^{\circ}$ and a blade tip speed of $244 \mathrm{~m} / \mathrm{sec}(800 \mathrm{ft} / \mathrm{sec}$ ). This gives a nominal takeoff advance ratio of 0.88 and power coefficient of 0.85 .

Figure 1 shows a straight wing installed downstream of the propeller. Three different wing configurations were installed downstream of the SR-7A propeller to investigate the acoustic effects of propeller-wing interaction. These configurations included a straight wing and two $30^{\circ}$ swept wings using the supercritical airfoil section (ref. 6). Only the data from the straight wing will be used in this paper. The straight wing chord was $0.61 \mathrm{~m}(2.0 \mathrm{ft})$. The propeller pitch change axis to wing leading edge spacing for the straight wing was 0.54 wing chords or 0.53 propeller diameters. In addition, the straight wing angle of attack could be changed relative to the propeller axis to explore the effect of propeller "droop angle". Droop angle is defined in this paper as the angle of the propeller axis relative to wing chord measured negative downward, as shown in figure 3.

\section{Blade Mounted Pressure Transducers (BMT's)}

Several Kulite miniature pressure transducers were mounted on two different blades in positions shown in figure $4(a)$. Two chordwise stations were used at both the 0.75 and 0.88 radius, while only the 0.1 chord station was used at 0.65 radius. The BMT's measuring the suction surface were all mounted on one blade while the pressure surface measurements were made on a second blade. The two instrumented blades were always adjacently mounted in the hub to measure flow properties from the same blade passage. The transducers were mounted to 
measure the pressure through a $1.55 \mathrm{~mm}$ diameter hole drilled through the blade as shown in figure 4(b). An RTV silicone adhesive was used for bonding in order to insure that the transducers were strain isolated from the blade. The RTV adhesive was also used to fair the BMT into the blade surface.

The signals from the BMT's are taken off the rotor through a rotary transformer. Transducer excitation is a $30 \mathrm{kHz}$ signal brought across the rotary transformer. The transducer output amplitude modulates the $30 \mathrm{kHz}$ carrier which is demodulated, amplified, and recorded on FM tape. The system frequence response was $10 \mathrm{kHz}$ or 65 to 130 shaft orders ( $P$ orders) depending on rpm.

The recorded BMT signals, along with the once-per-revolution pulse were digitized at rate of 128 samples per revolution. The digital information was then processed on a mainframe computer to produce 100 time ensembles of ten revolutions each. These were averaged (time domain averaging), and fast Fourier Transforms (FFT's) were taken to produce enhanced spectra and phase (azmuthal) angles. In addition, FFT's were taken of the individual time ensembles of data and then averaged in the frequency domain. These spectra were only used to monitor data quality. All spectra produced are in terms of shaft orders $(P)$.

\section{RESULTS AND DISCUSSION}

The propeller alone configuration was run first so that the inflow angle was known. The pressure response for all the BMT locations was measured as a function of inflow angle. The propeller axis was set to various angles of attack ranging from $-10^{\circ}$ to $+15^{\circ}$. Next the wing was installed downstream of the propeller and the blade pressure response was measured over wing angles of attack ranging from of $-2^{\circ}$ to $+8^{\circ}$ and engine droop angles from $+2^{\circ}$ to $-4^{\circ}$. The equivalent inflow angle was then determined by matching the measured first harmonic (one $P$ ) response to that of the propeller alone configuration. In effect, the BMT's were calibrated in terms of the propeller inflow angle and then used to measure unknown inflow conditions. The flyover noise in terms of the blade passing frequency (BPF) tone level was then correlated with the inflow angles for the propeller for both propeller/wing and propeller alone configurations.

\section{Propeller Alone}

Both unsteady blade surface pressure and noise measurements were made with the propeller axis set at angles between $-10^{\circ}$ (pitched down) and $+15^{\circ}$ to the tunnel flow. The blade angle was set at $37.8^{\circ}$ and the tip speed was varied between 183 to $290 \mathrm{~m} / \mathrm{sec}(600$ to $950 \mathrm{ft} / \mathrm{sec})$. The advance ratio, J, corresponding to this tip speed change was 1.18 to 0.74 . The noise measurements will be discussed in a later section of this paper.

A typical set of pressure waveforms for a case where there is an inflow angle to the propeller is shown in figure 5 . Here the propeller was run at an angle of 100 to the flow and 100 synchronous averages were used, although little sample to sample variations occurred. The convention used for blade azimuthal angle, $\psi$, is that $0^{\circ}$ corresponds to the vertical direction for an aircraft installation, with increasing angle measured in the direction of rotation. For this test series, $0^{\circ}$ is toward the near wall, as shown in figure 2. 
The BMT results shown in figure 5 are for both the pressure and suction surface at the 0.75 radius and 0.1 chord location for a tip speed of $244 \mathrm{~m} / \mathrm{sec}$ $(800 \mathrm{ft} / \mathrm{sec})$ corresponding to a $\mathrm{J}$ of 0.88 . The angular inflow to the propeller causes an approximately sinusoidal variation in blade angle of attack as it rotates. The magnitude of this variation is less than the angle the propeller axis makes with the flow due to the blade advancing into the flow as the blade angle increases and retreating as the blade angle decreases. This vector diagram effect is a function of blade radial location and advance ratio. Figure 6 shows this effect by using an expression similiar to, but more general than equation (9) of reference 7 (note: $J$ is defined differently in this reference) to generate the curves. The two curves shown represent a typical takeoff/approach condition ( $J=1$ ) and a cruise condition $(J=3)$. For the data presented in this paper, the $J=1$ curve is a good guide to the effect of radius and the change in $\alpha_{B}$. The 0.65 radius location has a $\Delta \alpha_{B}= \pm 0.94$ for $\alpha_{p}=5^{\circ}$. At 0.88 radius the $\Delta_{\alpha_{B}}= \pm 0.58$ or only 62 percent of the $\Delta \alpha_{B}$ seen at the 0.65 radius station. The $\Delta \alpha_{B}$ is much larger for the $J=3$ curve, while the percent change with radius is lower than for $J=1$. The effect of sweep was not included in figure 6 . The effective angle of attack change with radius would be still larger since, the sweep angle increases with radius for a large part of the blade span.

The change in blade angle of attack is included in figure 5 in order to show the phase relation between the pressure and its forcing function. The pressures on opposite surfaces are roughly $180^{\circ}$ out of phase. The pressure surface lags the angle of attack curve by $16^{\circ}$. Only a very limited amount of phase angle data will be presented since this paper uses the magnitude of the pressure response to investigate noise.

The spectra for the two BMT waveforms presented in figure 5 are shown in figure 7. The suction surface pressure has considerably more harmonic content than the pressure surface, particularly in the lower shaft orders (2-4P). These spectra are typical of the pressure and suction surfaces at most of the measuring stations. The rest of the discussion of pressure response in this paper will be centered on the fundamental frequency. The magnitude of the fundamental shaft order ( 1 P) RMS pressure was divided by the local dynamic pressure, $q_{r}$, for the radial station of the BMT to obtain a pressure coefficient, $C_{p l}$. The relative Mach number, $M_{r}$ for the radial location of the BMT and tunnel static pressure were used to calculate $q_{r}$. This 1 p pressure coefficient is shown at all ten locations as a function of advance ratio, $\mathrm{J}$, in figures 8 and 9 for the pressure and suction surfaces respectively.

As shown in figure 8 , very large changes in unsteady pressure coefficient occur on the suction surface. There seems to be a pattern in the results near the leading edge ( 0.1 and 0.15 chord). The 0.88 radius, 0.15 chord location shows a very rapid initial decrease in response to increased loading (decreasing J) and then a more gradual drop. This suggests that there may be a peak at a $\mathrm{J}$ above 1.18. The 0.75 radius 0.1 chord location shows a large peak at a $\mathrm{J}$ of 0.94 while the 0.65 radius 0.1 chord station seems to be approaching a peak beyond the range of the data (below a $\mathrm{J}$ of 0.83 ). These peaks in the response of the suction surface leading edge BMT's seem to be moving radially inward as the loading increases.

There may be a connection between the data presented here and the motion of a leading edge vortex. The studies in reference 7 show oil flow visualization on similiar blades that suggest the presence of a leading edge vortex that 
merges with the tip vortex when loading conditions are similiar to those in this investigation. The photographs presented in reference 8 were used to create figure 10, which shows the locations of the reattachment lines for three different advance ratios on the CRP-Xl blade at a flight Mach number of 0.25 . Although the blade loading and Mach number in figure 10 are similar to those in this investigation, it should only be used as a qualitative guide to the flow conditions present in this data. The vortex system near the leading edge migrates from the tip of the blade toward the hub as the loading increases from $\mathrm{J}=1.67$ to 1.05 . Not only does the vortex move to a lower radius but downstream along the chord, to a point that at high loading, the reattachment line has moved to the trailing edge at a substantial distance from the tip. It is possible that this growth of the vortex system with loading is responsible for the progression of the peak in the response of the unsteady pressure to lower radial stations as loading increases. It also appears that the vortex can grow beyond the 0.5 chord station at the 0.88 radius location. This might account for the high unsteady loading peak for this location shown in figure 8 . Generally, the 0.5 chord station has a low response typical of the 0.75 radius data. It could be speculated that if the blades were loaded beyond the limits of the present data, even the station at 0.75 radius and 0.5 chord would have a response peak similiar to the other stations. Details such as the location of the vortex corresponding to the peak unsteady pressure response are not apparent in this investigation.

The phase angles shown in figures 8 and 9 are in terms of lead or lag relative to the forcing function (change in angle of attack). As shown in figure 5 , on the pressure surface the forcing function has a maximum at an azimuthal angle of $90^{\circ}$. The suction surface forcing function is $180^{\circ}$ out of phase with the pressure surface and has a maximum at $\psi=270^{\circ}$. With one exception all the phase angle data is grouped together in figure 8 . The general trend is a progression from a $10^{\circ} \mathrm{lag}$ to one of $25^{\circ} \mathrm{lag}$ as the loading is increased. It is not known why the 0.75 radius, 0.5 chord station has a phase lead and increases with loading. The low pressure amplitude at this station makes the determination of phase angle less accurate.

Figure 9 shows the response of the same five stations on the pressure surface. As might be expected, the magnitude of the pressure coefficient is generally lower on the pressure surface than the suction surface. There are strong trends with loading and the phase angles are all near $10^{\circ} 1 \mathrm{ag}$. Although the steady loading is increasing with decreasing $\mathrm{J}$, the periodic change in blade angle of attack is decreasing, as previously discussed. These two opposite effects may explain the flat unsteady pressure response with $\mathrm{J}$. The trend in the BMT's near the leading edge to higher unsteady response as the radius decreases can also be explained by changes in the periodic variation in blade angle of attack. As mentioned previously, there is a significant increase in the periodic blade angle of attack change with decreasing radius.

The 1 p pressure coefficients for both the pressure and suction surfaces are plotted against the angle-of-attack of the propeller axis, $\alpha p$, for a $J$ of 0.88 , as shown in figure 11. The responses from six of the BMT's at various locations are plotted for both positive and negative $\alpha p$. The negative $C_{p l}$ values are $\sim 180^{\circ}$ out of phase with the positive values. The response at 0.75 radius ( $\mathrm{fig}$. $11(\mathrm{l})$ ) seemed normal, with the suction surface near the leading edge showing very high response to the $1 \mathrm{P}$ variation in blade loading. The corresponding pressure surface location has significantly less response, which is analogous to the expected steady pressure profiles. The response at 0.88 
radius (fig. $11(b)$ ) also has higher response on the suction surface. However, the 0.15 chord location shows lower amplitude response than the 0.5 chord location, which is not expected from steady-state pressure profiles on this blade section. The unusual pressure response behavior was. covered in the discussion of figures 8 and 9 . Recall that this behavior may be related to the change in the location of the leading edge vortex.

All stations have a fairly linear response to $\alpha_{p}$, which indicates no major flow changes are occurring at the angles of attack included in this investigation. The curves in figure 11 do not go through the origin but seem to cross the horizontal axis at about $-1.5^{\circ}$. This might be a result of the misalignment of the propeller axis with the tunnel axis, a tunnel flow distortion caused by the propeller not being mounted at the center of the test section, or residual electrical signals generated by the rotary transformer used to transmit the BMT signals.

\section{Propeller-Wing Installation}

A straight (unswept) wing of $0.61 \mathrm{~m}(2.0 \mathrm{ft}$ ) chord was installed downstream of the propeller. The spacing between the propeller pitch change axis and wing leading edge was 0.54 wing chords. The droop angle, $\delta$ as shown in figure 3 was adjusted between $+2^{\circ}$ and $-4^{\circ}$ in $2^{\circ}$ increments. A range of wing angle of attack, $\alpha_{w}$ was run between $0^{\circ}$ and $+8^{\circ}$. As indicated in figure 2 , the wing causes an additional upwash which results in an increase in the local propeller inflow angle, $\alpha_{L}$. This additional upwash is the difference between $\alpha_{p}$ and $\alpha L$ and is assumed uniform here.

An example of the measured pressure response for the propeller-wing installation is shown in figure 12. Here $C_{p 1}$ for the 0.75 radius and 0.1 chord location on the suction surface is plotted against $\alpha_{w}$ for each droop angle tested. At only one droop angle, $\delta=-4^{\circ}$, did the curve ever go through zero, indicating no angular inflow. Some lowering of the slope of these curves is evident at the very high dynamic loading above a $C_{p l}=0.3$.

A more revealing way of using the measured pressure response of the propeller blades with the wing installed is to use it to determine the local inflow angle, $\alpha_{L}$. This can be done by setting the $C_{p l}$ from the wing installation equal to that of the propeller alone configuration. This was done by entering the propeller alone response curves, figure 11 , with the values of $C_{p l}$ from the wing data (example, fig. 12) and reading the corresponding propeller angle of attack. It was assumed that the local inflow angle and propeller angle of attack are the same $\left(\alpha_{p}=\alpha_{L}\right)$ for the propeller alone case. When this was done for all six measuring stations, the small station to station variation in $\alpha$ was eliminated by averaging all stations. The resulting local inflow angles were then plotted against wing angle of attack as shown in figure 13 .

The $\alpha L$ increases very nearly linearly with $\alpha_{w}$ at a rate of $1.5^{\circ}$ for every degree of $\alpha_{w}$ for all four droop angles. The droop angle curves are spaced $\sim 2^{\circ}$ apart for every $2^{\circ}$ change in droop angle: With the wing at zero angle of attack there is approximately a $2^{\circ}$ upwash at the propeller inlet for $\delta$ $=0^{\circ}$. In order to keep the local inflow angle at zero degrees, the curves can be generalized by the following expression: 


$$
\begin{gathered}
\delta \simeq-2-\left(1.5 \alpha_{W}\right) \\
\text { for } \alpha_{L}=0^{\circ}
\end{gathered}
$$

Hence, a relatively large value of droop is necessary to obtain a propeller inflow angle of zero. For example, when $\alpha_{w}=4^{\circ}$ it would take a droop angle of $-8^{\circ}$ to align the propeller with the flow.

With the local inflow angle of the propeller known over a wide range of droop angles and wing angles of attack, a correlation can be found for the flyover noise data. Figure 14 shows this correlation by plotting all the maximum flyover blade passing frequency tone levels against $\alpha L$. This data includes both the propeller/wing configurations and the propeller alone cases. Almost all the data collapses to within one decibel (acoustic data repeatability) on this plot. This indicates that the noise is controlled by the local inflow angle, which also sets the unsteady blade loading. The first order installation effect of the wing is a uniform inflow angle at the propeller. Thus, a propeller operating at an angle to the flow might be expected to generate the same noise as a wing installation causing the same inflow angle. For this propeller there is approximately $0.6 \mathrm{~dB}$ increase in the maximum BPF flyover noise for every degree increase in inflow angle.

A comparison of the pressure waveform and spectra for the propeller alone and propeller/wing installation at the same local inflow angle is useful in determining just how similar both inflow conditions are. Figure 15 shows a comparison between wing and no wing pressure waveforms for an inflow angle of $10.0^{\circ}$. This data is for a BMT at 0.75 radius and 0.1 chord on the suction surface. The waveforms are almost identical except for a small relative phase $1 \mathrm{ag}\left(11^{\circ}\right)$ in the wing case. Figure 16 shows a spectral comparison of the same two BMT's shown in figure 14. The full enhanced (time domain synchronous averaged) spectrum for the propeller alone is shown while only the tone levels are indicated for the wing data. The wing seems to have little effect on the results since the spectrum shows only small increases in the 2 and $4 \mathrm{P}$ levels, and slight decreases in some of the levels in the vicinity of 10P. Although the wing increases the $2 P$ level and this could increase the noise, the $1 P$ level is still almost an order of magnitude higher. This indicates that the effect of the wing installation is primarily one of nearly uniform upwash with all other effects being second order or less. This is consistent with the noise data correlation presented.

\section{SUMMARY OF RESULTS}

A single rotation model propeller (SR-7A) was tested at simulated takeoff/approach conditions (0.2 Mach) in the NASA Lewis $9 \times 15$ Anechoic Wind Tunnel. Both unsteady blade surface pressures and noise measurements were made for a tractor configuration with a propeller/straight wing and propeller alone configurations. The angle between the wing chord and propeller axis (droop angle) was varied along with the wing angle of attack to determine the effects on noise and unsteady loading.

1. A method was developed that uses unsteady blade pressure measurements to provide a quantitative indication of propeller inflow conditions, at lease for a uniform (across the propeller disk) inflow angle. This method involves calibrating each measuring stations on the blade in terms of the propeller 
inflow angle (propeller alone configuration) and then using these calibrations to determine an unknown inflow condition (propeller/wing configuration):

2. The wing installation caused a nearly uniform upwash at the prope1ler inlet as evidenced by the domination of the pressure spectra by the first shaft order. This inflow angle increased at a rate of almost 150 percent of that of the wing angle-of-attack for a propeller-wing spacing of 0.54 wing chords at a constant droop angle.

3. The flyover noise, as measured by the maximum blade passing frequency level, correlates closely with the propeller inflow angle ( $0.6 \mathrm{~dB}$ per degree of inflow angle) for all droop angles and wing angles-of-attack tested, including the propeller alone data. This is consistent with a uniform inflow angle caused by the wing installation, as indicated by the blade surface pressure measurements.

4. Large changes in the unsteady pressure responses on the suction surface of the blade were observed as the advance ratio was varied. The presence of a leading edge vortex may explain this behavior since changes in the location of this vortex would change with loading (advance ratio).

\section{REFERENCES}

1. Mikkelson, D.C., Mitche11, G.A., and Bober, L.J., "Summary of Recent NASA Propeller Research," Aerodynamics and Acoustics of Propellers, AGARD CP-366, AGARD, France, 1985, pp. 12-1 to 12-24. (NASA TM-83733).

2. Metzger, F.B., "Progress and Trends in Propeller/Prop-Fan Noise Technology," AIAA Paper 80-0856, May 1980.

3. Parzych, D., Shenkman, A., and Cohen, S., "Large-Scale Advanced Propfan (LAP) Performance, Acoustic and Weight Estimation," SP-06A83, Hamilton Standard, Windsor Locks, CT, Jan. 1984. (NASA CR-174782).

4. Whitlow, J.B. Jr. and Sievers, G.K., "Fuel Savings Potential of the NASA Advanced Turboprop Program," NASA TM-83736, 1984.

5. Woodward, R.P., "Measured Noise of a Scale Model High Speed Propeller at Simulated Takeoff/Approach Conditions," AIAA Paper 87-0526, Jan. 1987. (NASA TM-88920).

6. Welge, H.R. and Crowder, J.P., "Simulated Propeller Slipstream Effects on a Supercritical Wing," NASA CR-152138, 1978.

7. Dobrzynski, W.M., "The Effect on Radiated Noise of Non-Zero Propeller Rotational Plane Attitude," AIAA Paper 86-1926, July 1986.

8. Vaczy, G.M. and McCormick, D.C., "A Study of the Leading-Edge Vortex and Tip Vortex on Propfan Blades," ASME Paper 87-GT-234, June 1987. 


\title{
ORIGTNAT PAGE IS OR. ROOR QUNITTY.
}

\author{
ingunar page n \\ OF PO
}

TABLE I. - SR-7A PROPELLER DESIGN CHARACTERISTICS

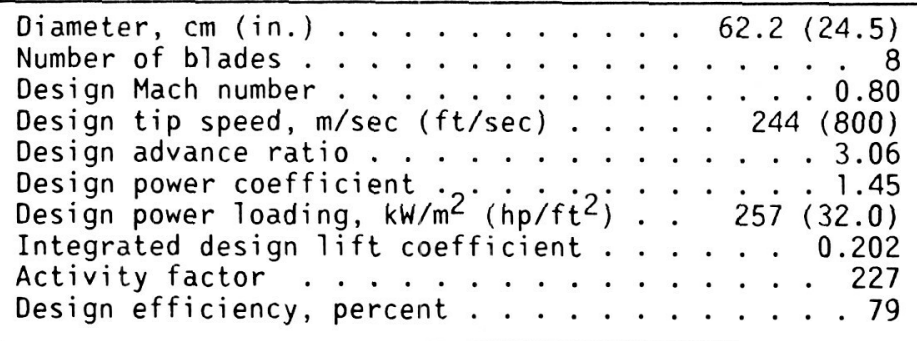

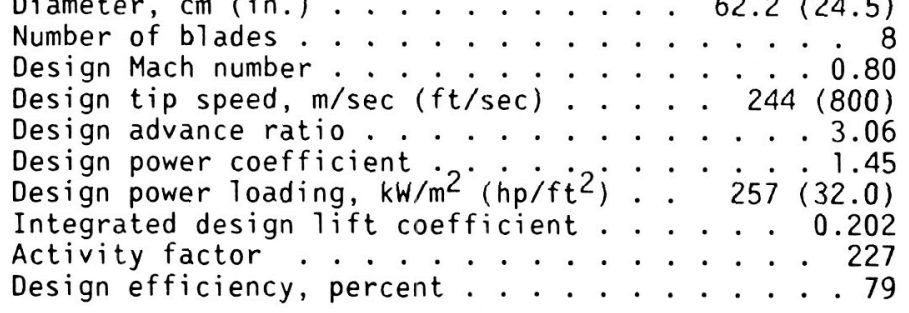

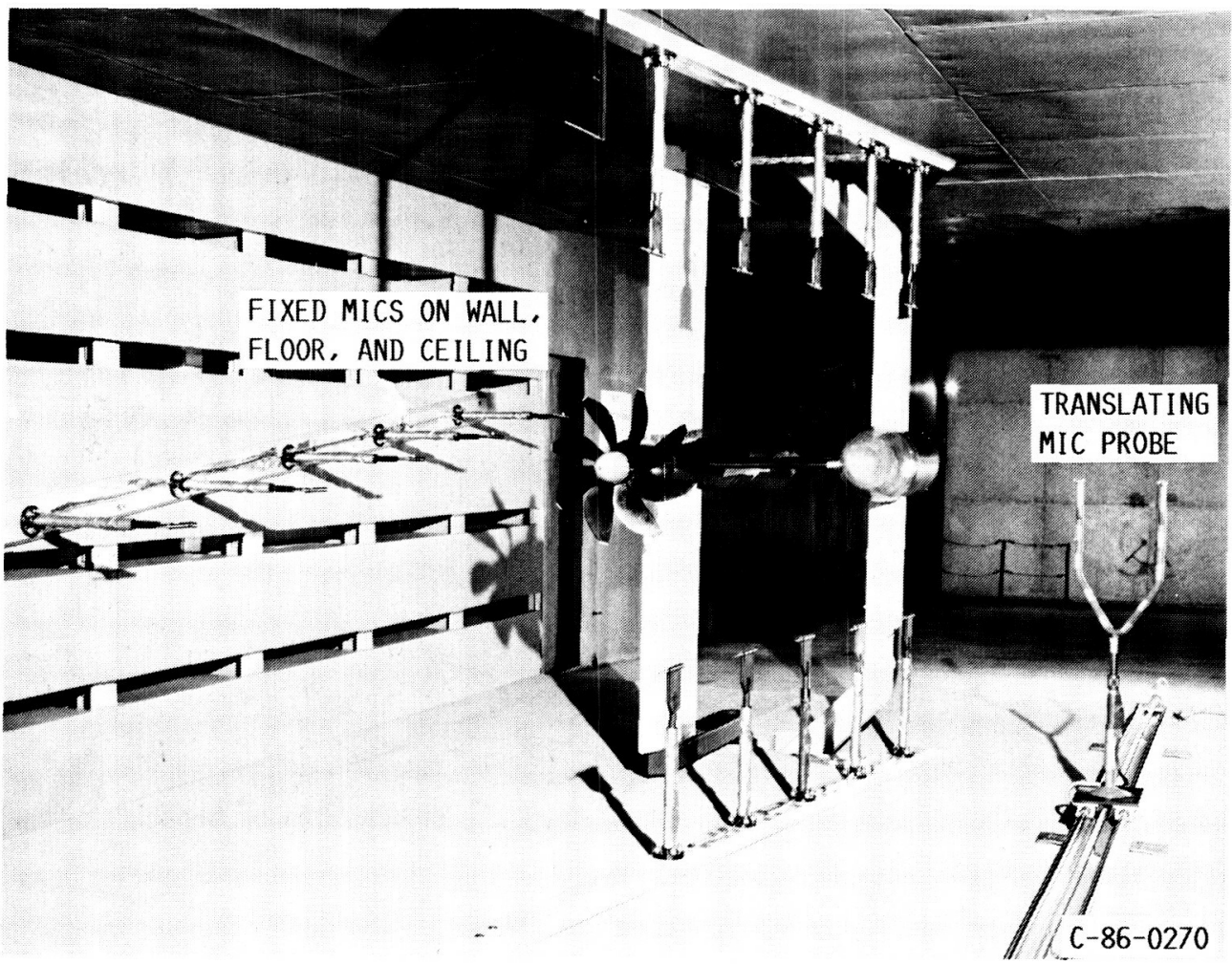

FIGURE 1. - PHOTOGRAPH OF SR-7A TURBOPROP IN 9- BY 15-FT ANECHOIC WIND TUNNEL SHOWING STRAIGHT WING INSTALLED. 


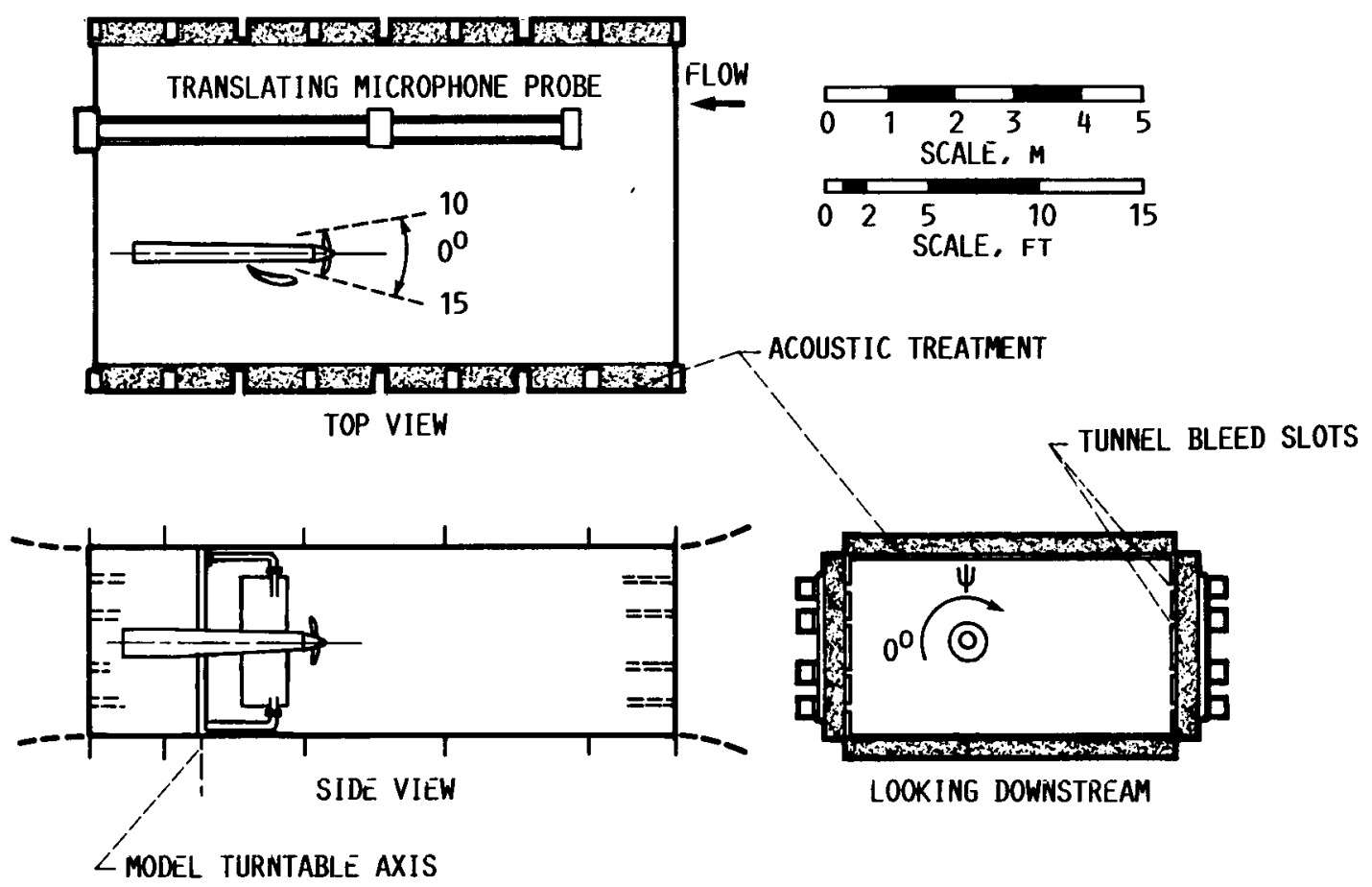

FIGURE 2. - PLAN VIEW OF THE 9X15 ANECHOIC WIND TUNNEL SHOWING THE SR-7A TURBOPROP INSTALLATION.

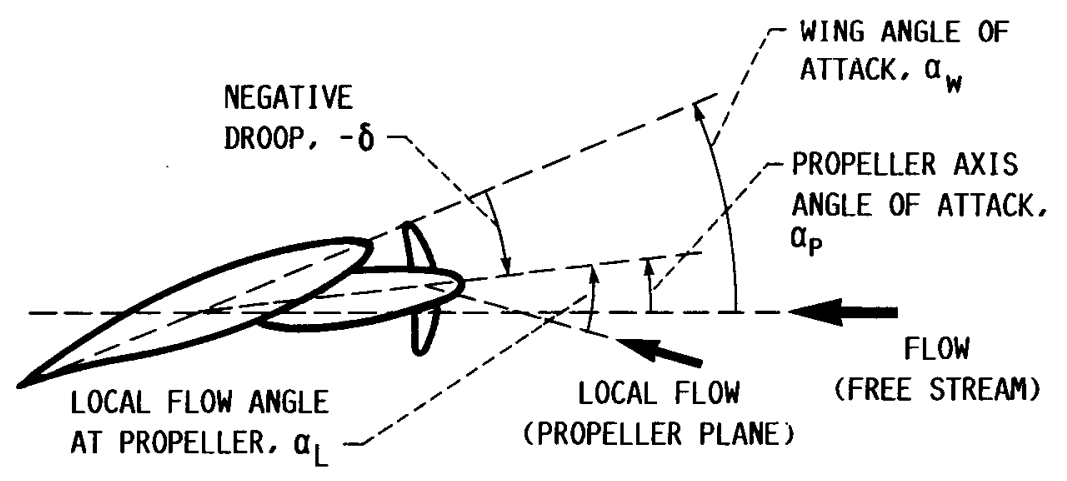

FIGURE 3. - PROPELLER AND WING GEOMETRY. 


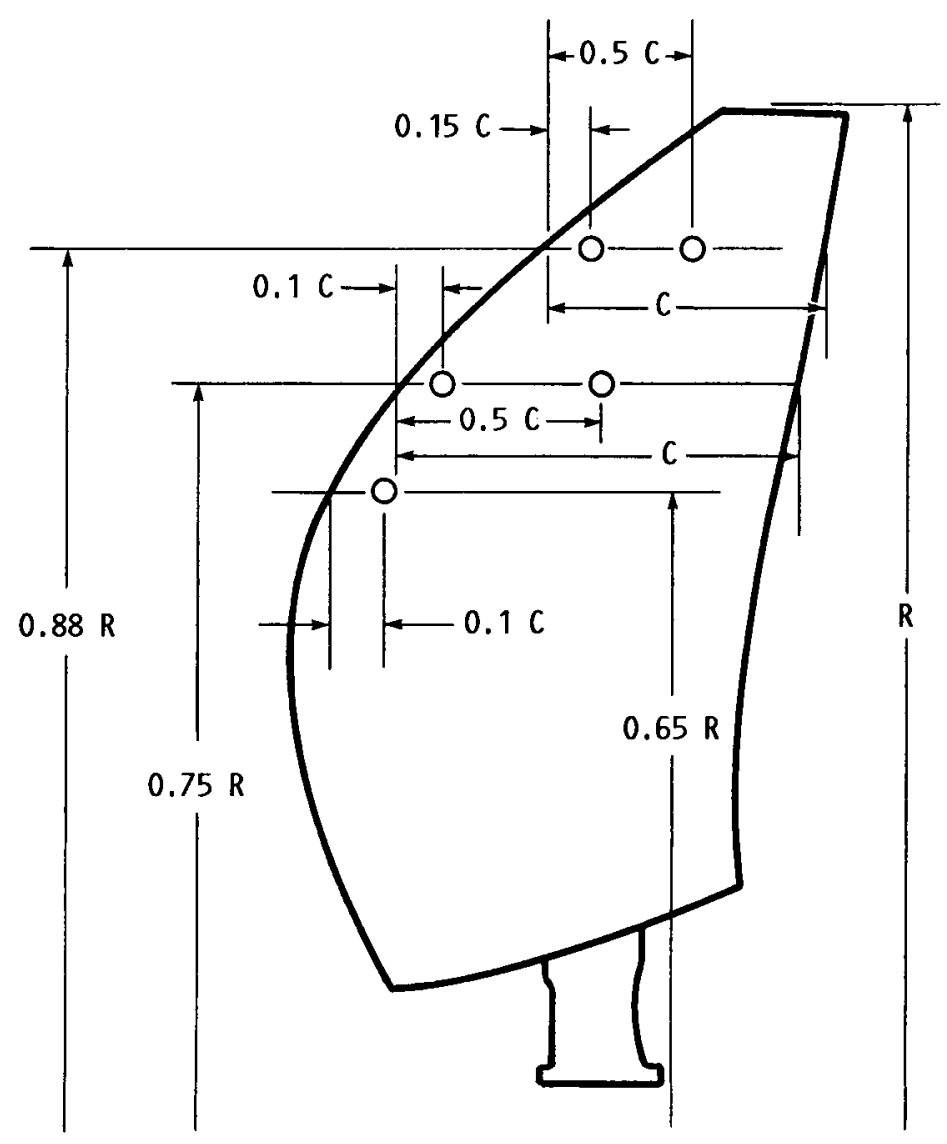

(A) PRESSURE TRANSDUCER LOCATIONS: TWO BLADES INSTRUMENTED, ONE ON PRESSURE SURFACE, THE OTHER ON SUCTION SURFACE.

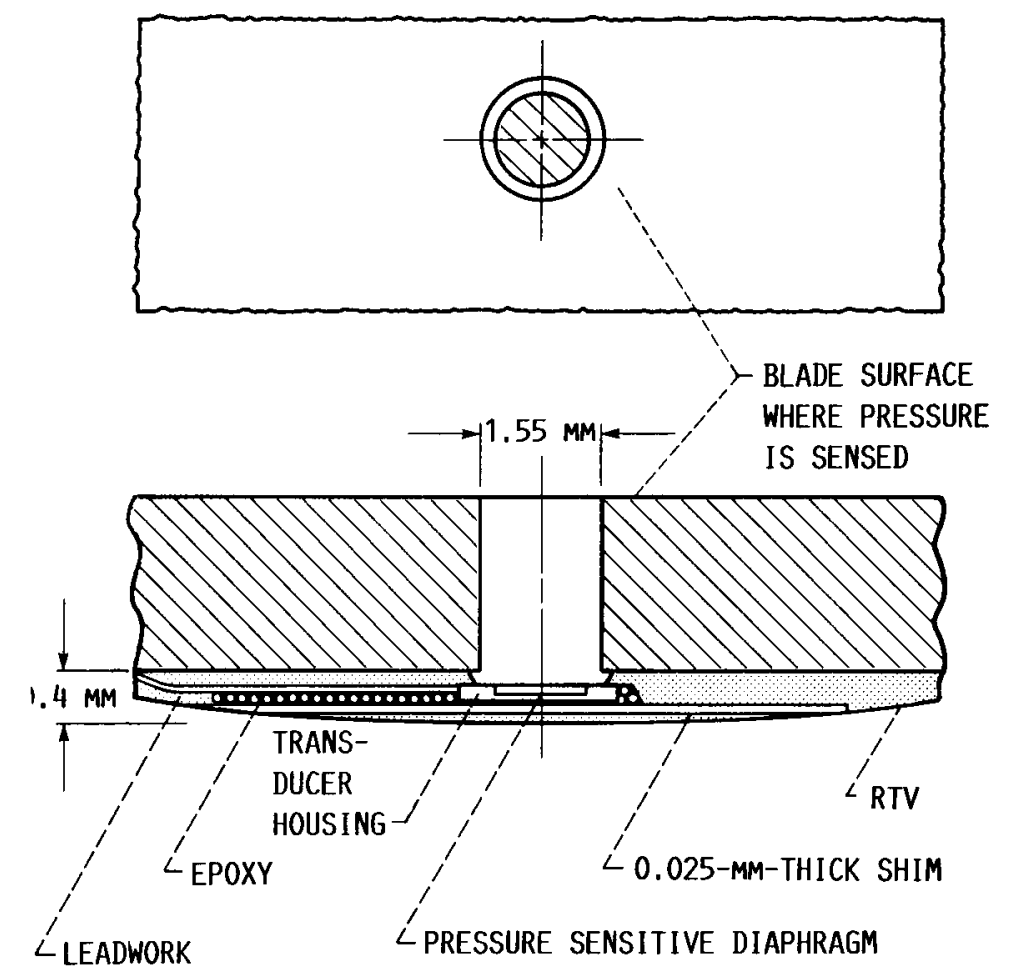

(B) TYPICAL INSTALLATION OF BLADE MOUNTED PRESSURE TRANSDUCER SENSING THROUGH BLADE.

FIGURE 4. - BLADE MOUNTED PRESSURE INSTRUMENTATION. 

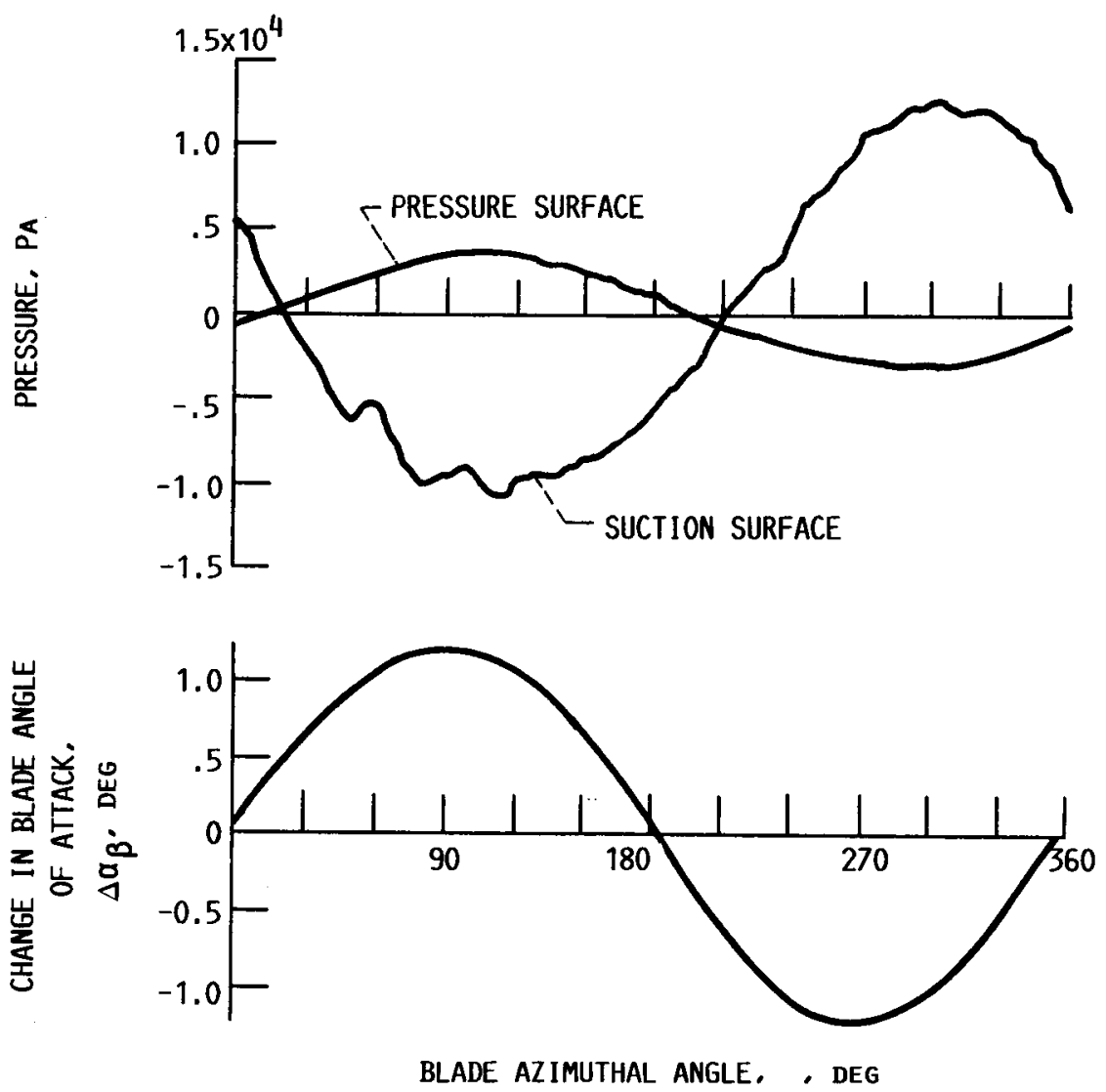

FIGURE 5. - PRESSURE WAVEFORM FOR A LOCATION OF 0.75 RADIUS AND 0.1 CHORD FOR A PROPELLER AXIS ANGLE-OFATTACK OF $10^{\circ}, \mathrm{J}=0.88, M_{\infty}=0.2$, TIP SPEED $=$ $244 \mathrm{M} / \mathrm{SEC}(800 \mathrm{FT} / \mathrm{SEC}), 100$ AVERAGES. 


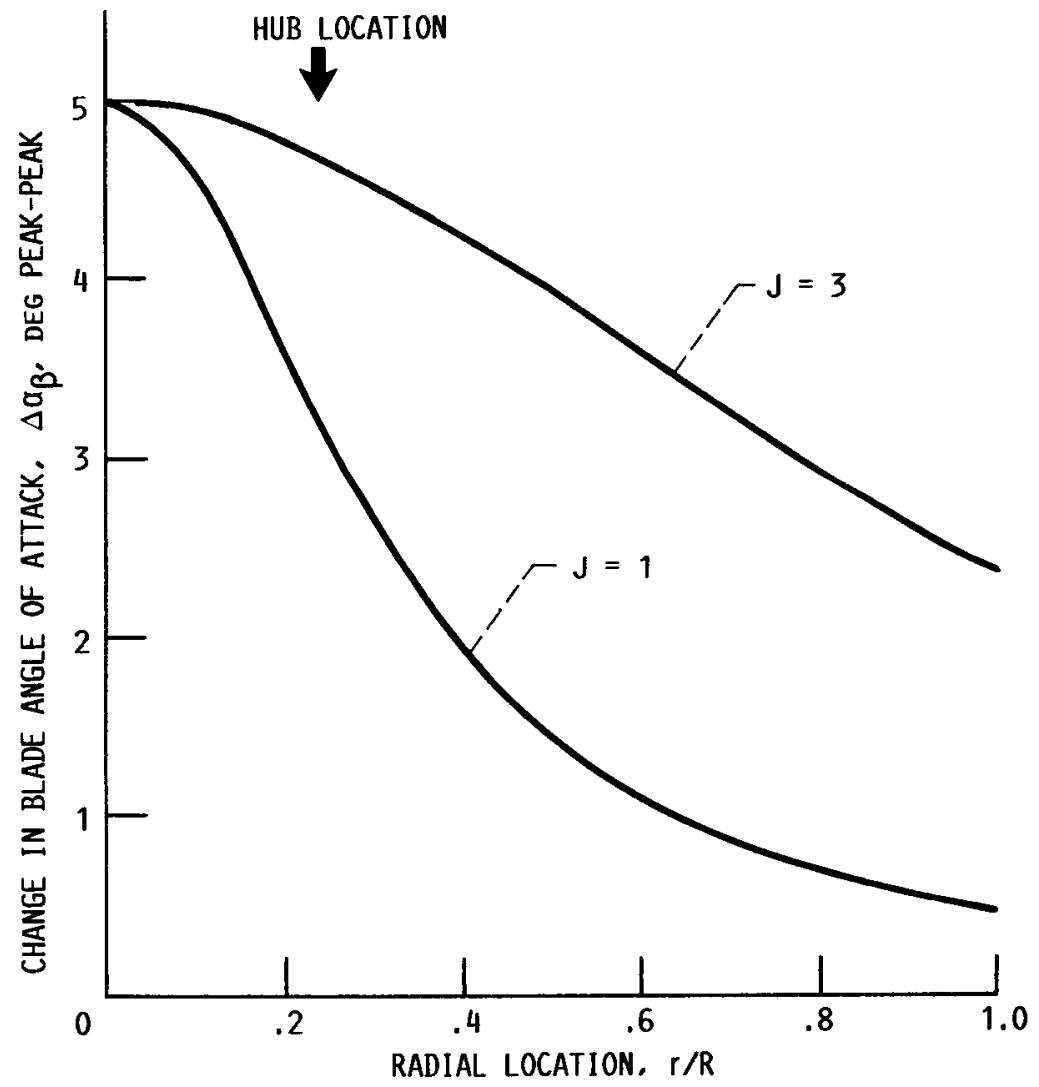

FIGURE 6. - EFFECT OF RADIAL LOCATION AND ADVANCE RATIO ON THE PERIODIC CHANGE IN BLADE ANGLE OF ATTACK FOR A PROPELLER WITH THE INFLOW AT $5^{\circ}$ TO THE AXIS. 


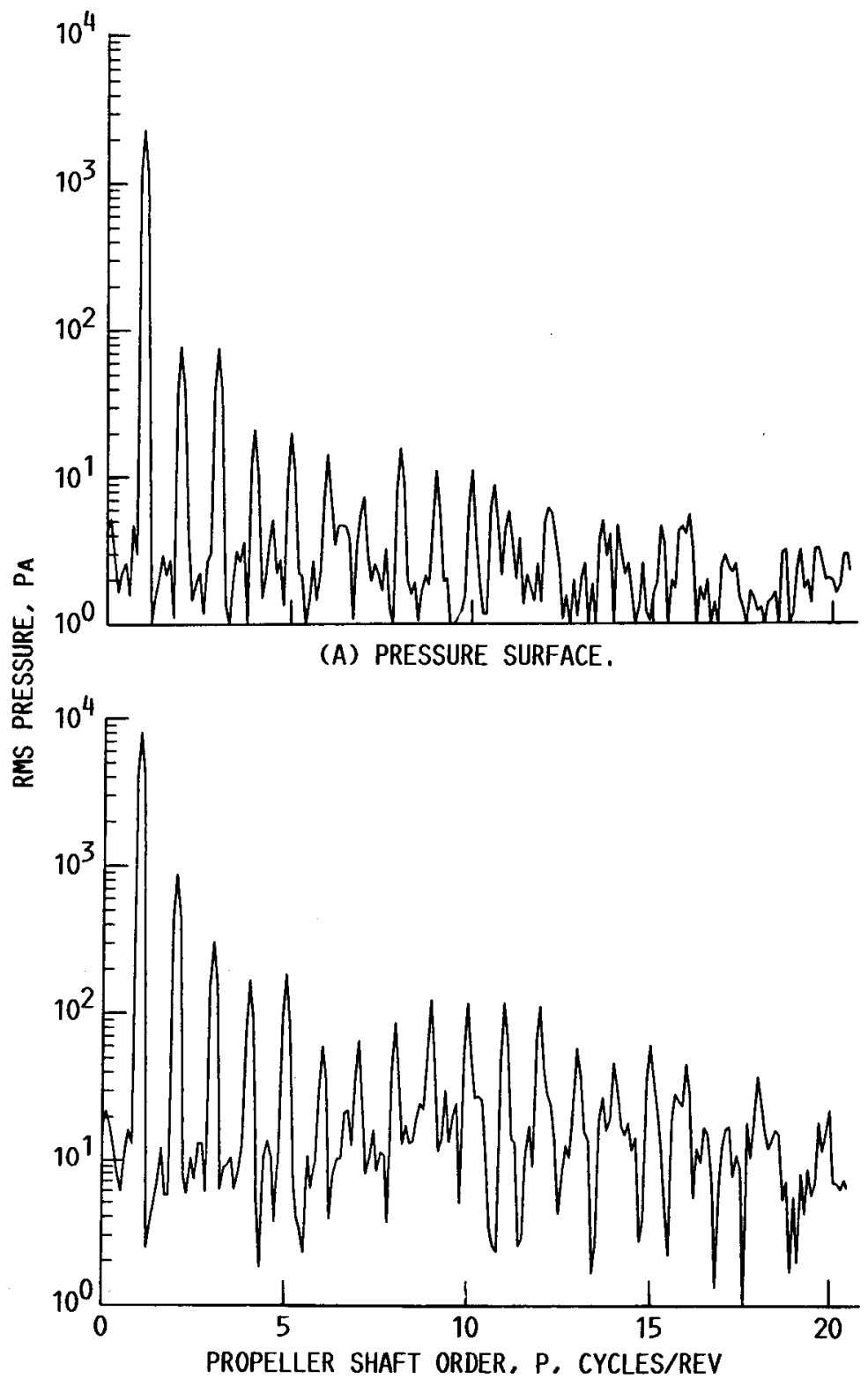

(B) SUCTION SURFACE.

FIGURE 7. - SPECTRA OF PRESSURE WAVEFORM AT 0.75 RADIUS AND 0.1 CHORD FOR PROPELLER AXIS ANGLE OF ATTACK OF $10^{\circ}, \mathrm{J}=0.88, \mathrm{M}_{\infty}=0.2$. TIP SPEED $=244 \mathrm{M} / \mathrm{SEC}(800$ FT/SEC), 100 AVERAGES. 

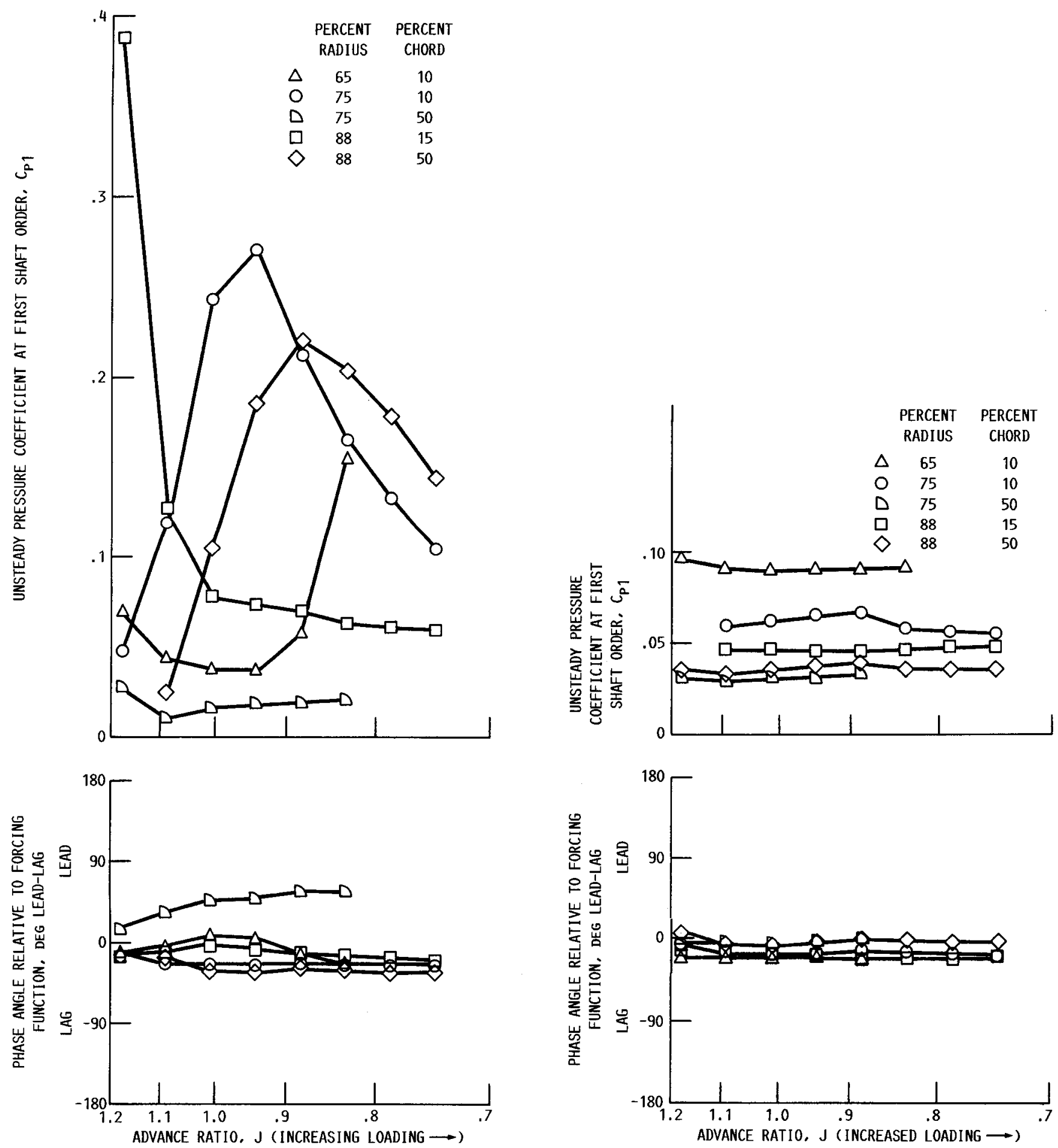

FIGURE 8. - UNSTEADY PRESSURE RESPONSE ON SUCTION SURFACE AS FUNCTION OF ADVANCE RATIO FOR PROPELLER AXIS ANGLE $\alpha_{p}=5^{0}$, BLADE SETTING ANGLE $\beta=37.8^{0}$. AND $M_{\infty}=0.2$.

FIGURE 9. - UNSTEADY PRESSURE RESPONSE ON PRESSURE SURFACE AS FUNCTION OF ADVANCE RATIO FOR PROPELLER AXIS ANGLE $\alpha_{p}=5^{\circ}$. BLADE SETTING ANGLE $\beta=37.8^{\circ}$, AND $M_{\infty}=0.2$. 


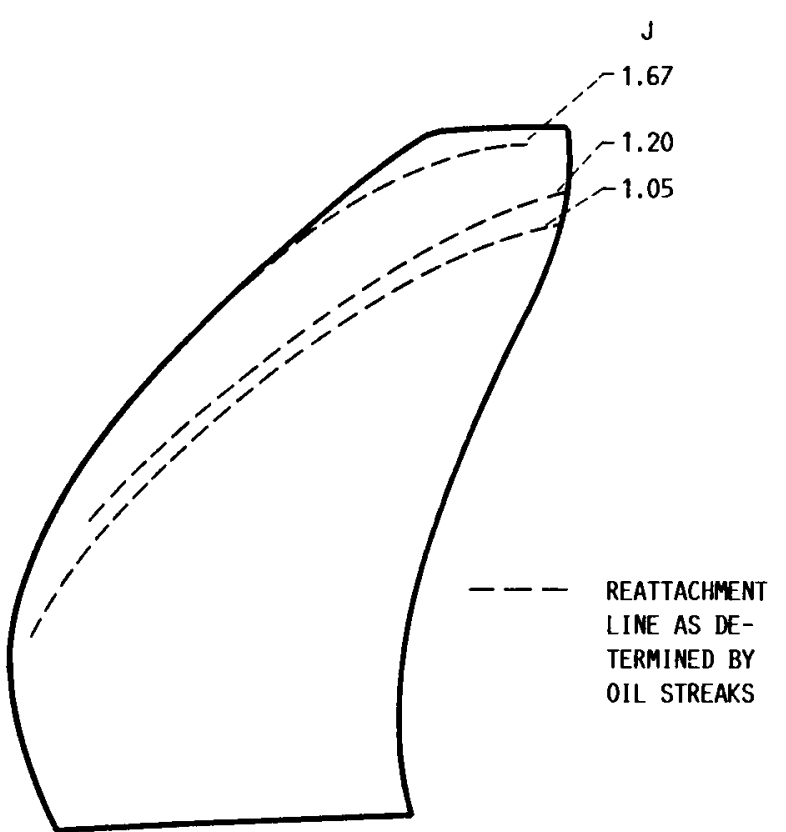

FIGURE 10. - EFFECT OF LOADING ON LOCATION OF LEADING EDGE VORTEX REATTACHMENT LINE. FROM PHOTOGRAPHS OF REFERENCE 7 (C. $M$. VACZY) CRP-X1 BLADE, $M_{\infty}=0.25$. BLADE SETTING ANGLE $\beta=39.78^{\circ}$.

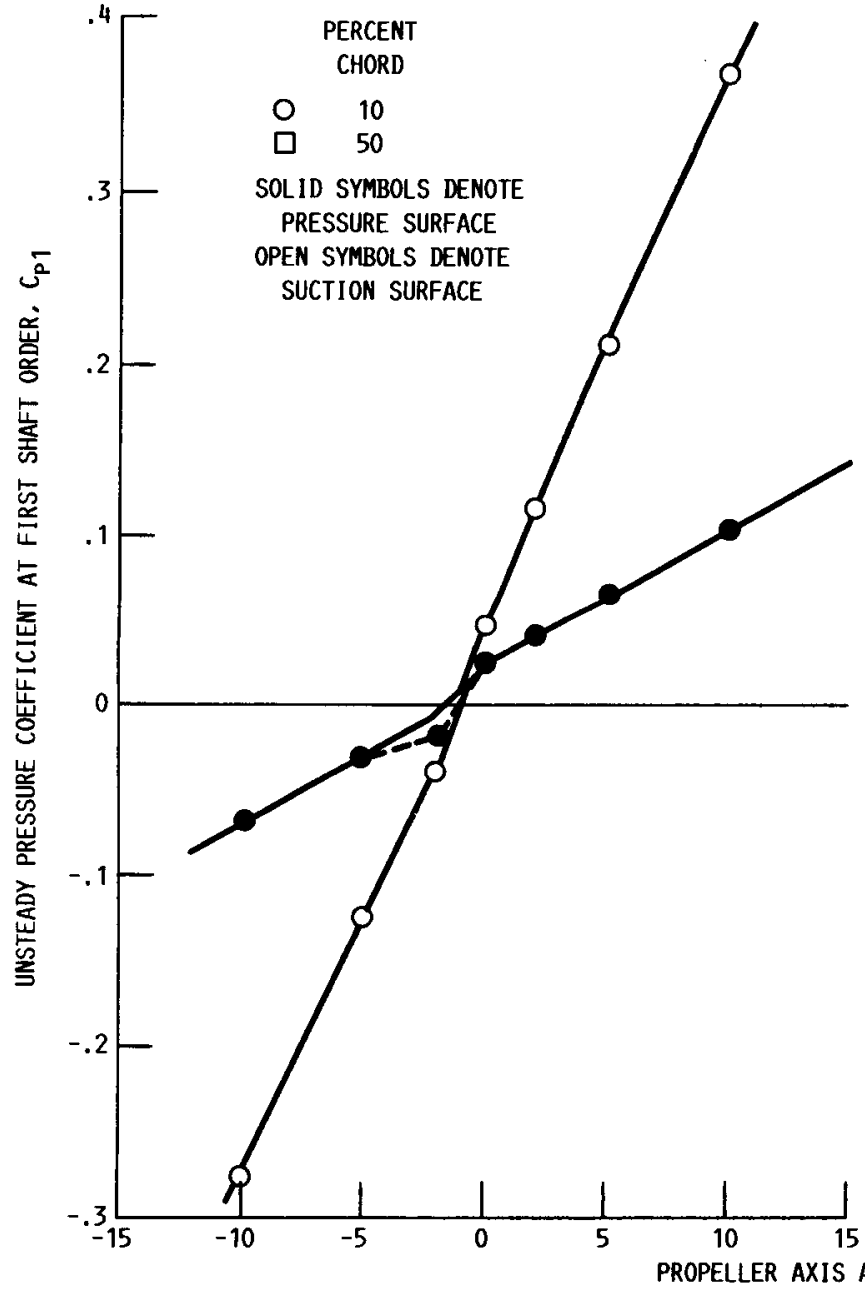

(A) 0.75 RADIUS

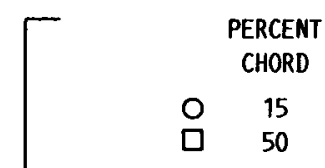

SOL ID SYMBOLS DENOTE PRESSURE SURFACE OPEN SYMBOLS DENOTE SUCTION SURFACE
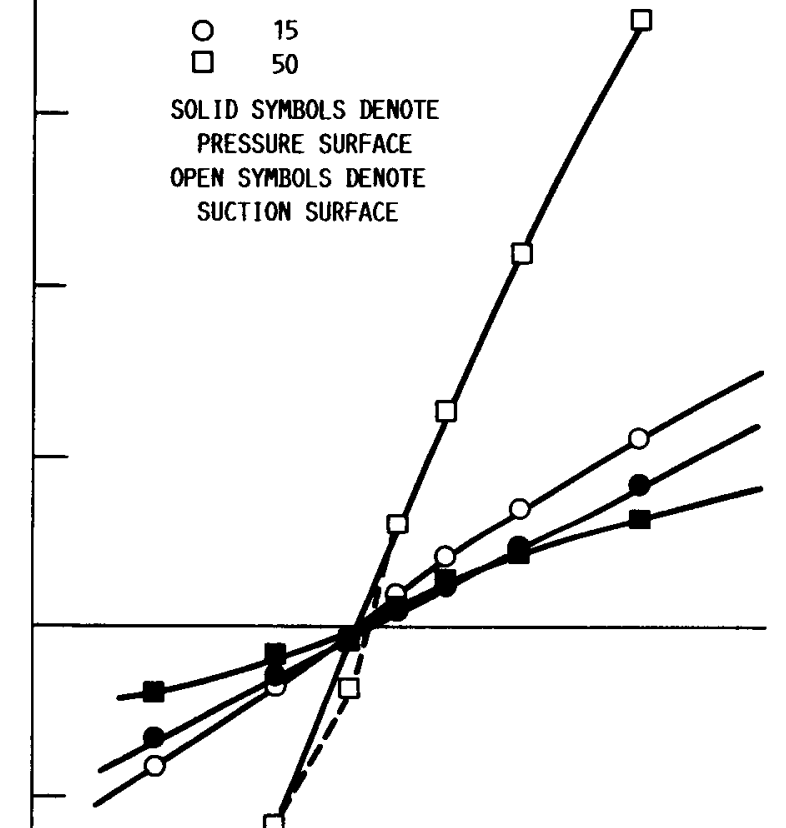

$-15$ 


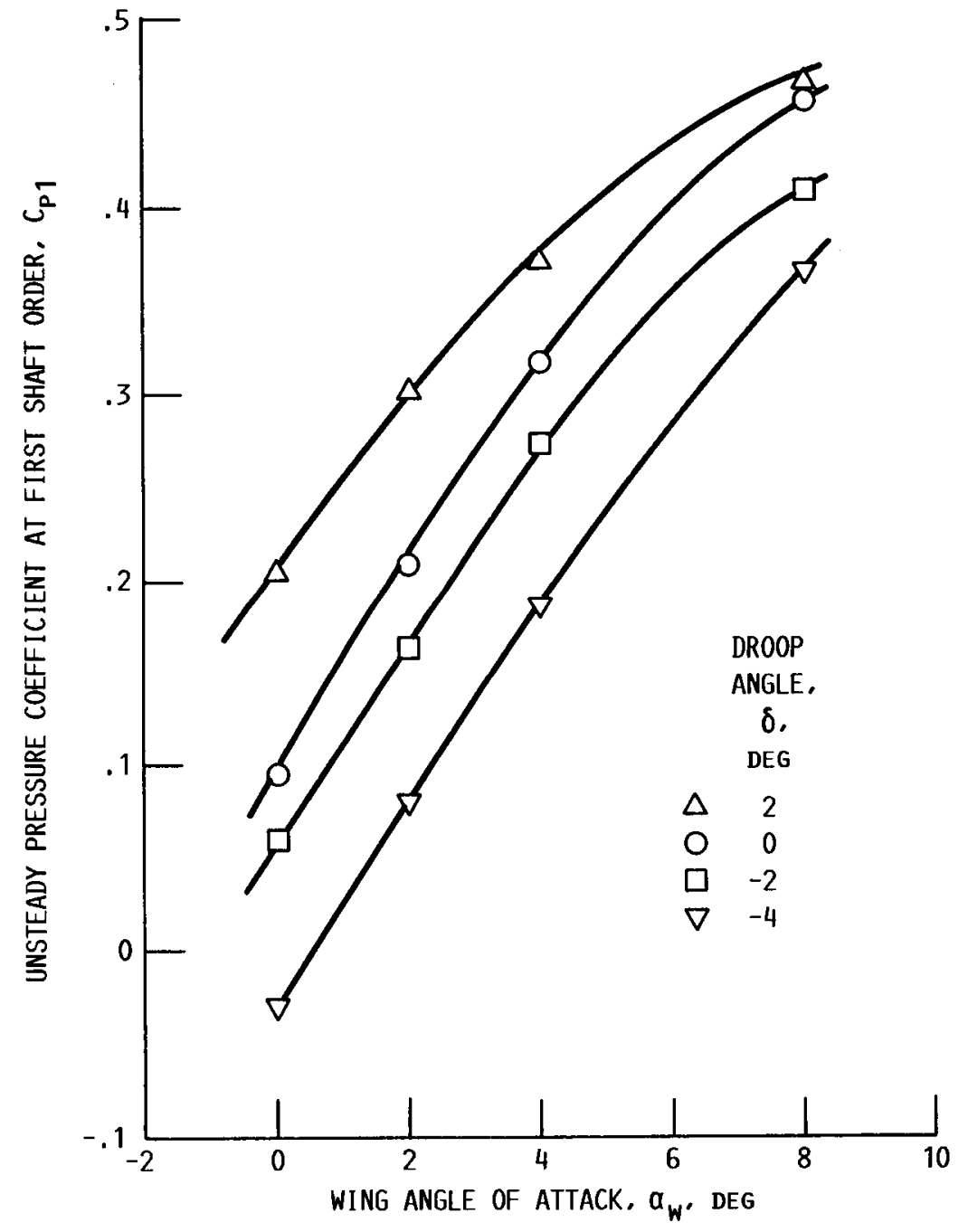

FIGURE 12. - PRESSURE RESPONSE AS FUNCTION OF WING ANGLE OF ATTACK FOR LOCATION OF 0.75 RADIUS AND 0.1 CHORD ON SUCTION SURFACE, $J=0.88, M_{\infty}=0.2$, TIP SPEED $=244$ $\mathrm{M} / \mathrm{SEC}(800 \mathrm{FT} / \mathrm{SEC})$. 


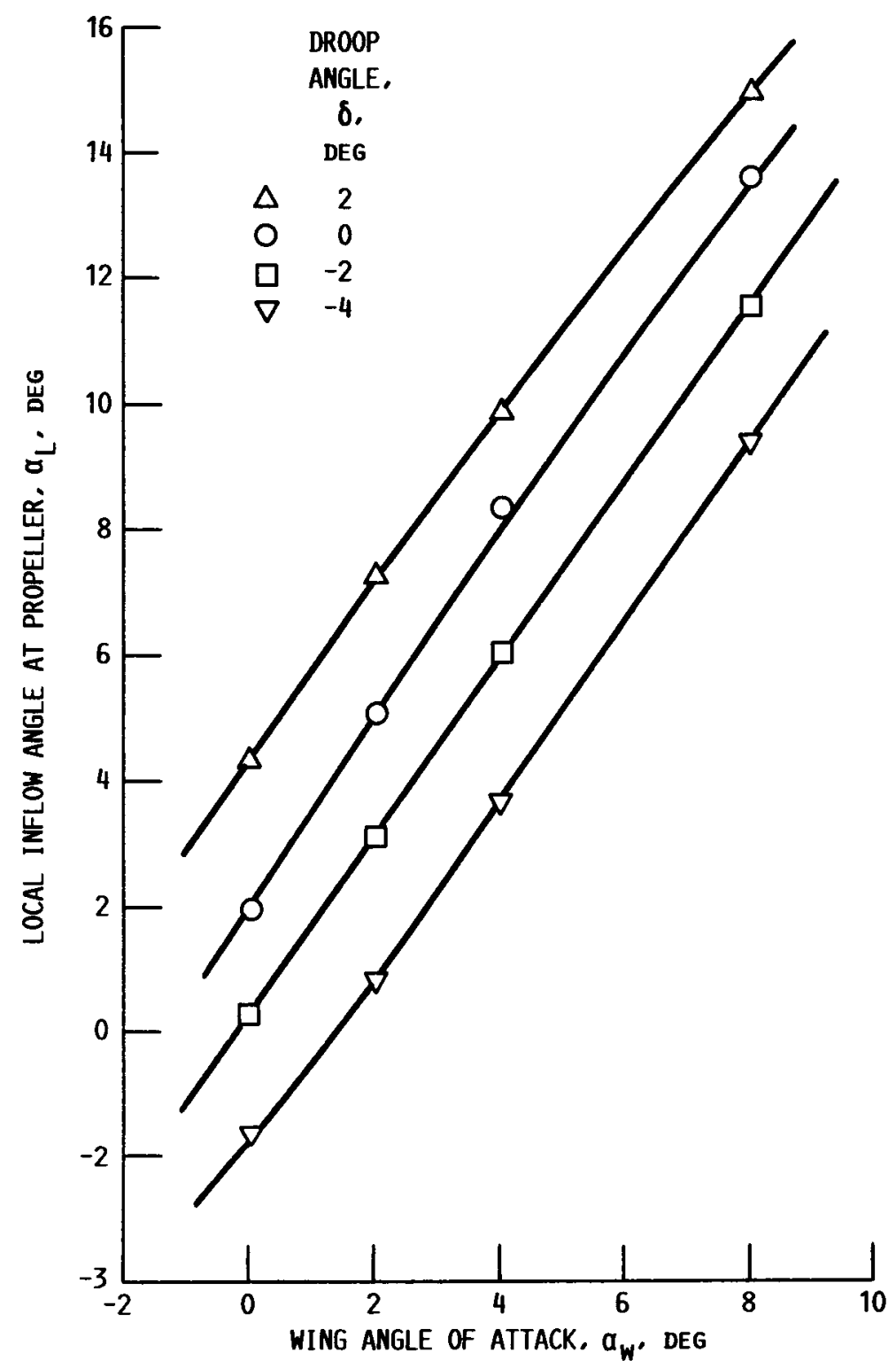

FIGURE 13. - LOCAL PROPELLER INFLOW ANGLE AS FUNCTION OF WING ANGLE OF ATTACK, $J=0.88, M_{\infty}=0.2$. TIP SPEED $=244 \mathrm{M} / \mathrm{SEC}(800 \mathrm{FT} / \mathrm{SEC})$. 


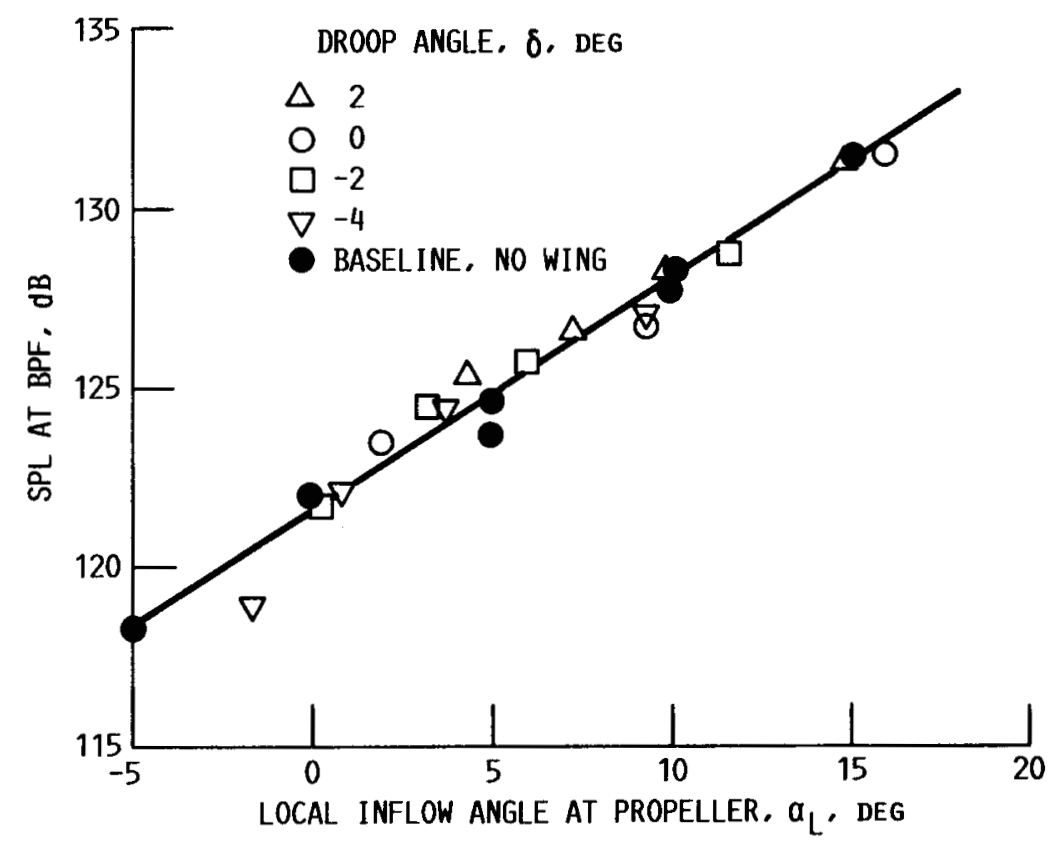

FIGURE 14. - MAXIMUM FLYOVER TONE NOISE AS FUNCTION OF LOCAL PROPELLER INFLOW ANGLE FOR STRAIGHT WING AND NO WING, $\mathrm{J}=0.88, \mathrm{M}_{\infty}=0.2$. TIP SPEED $=244 \mathrm{~m} / \mathrm{SEC}$ $(800 \mathrm{FT} / \mathrm{SEC})$.

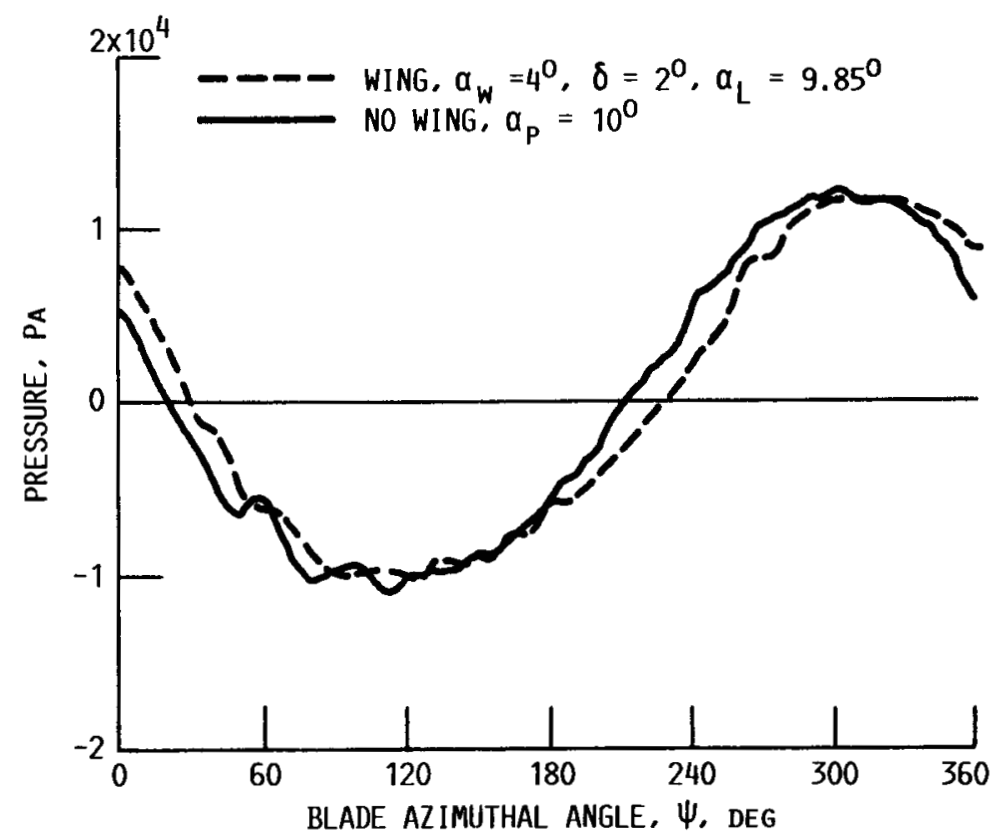

FIGURE 15. - COMPARISON OF WAVEFORM BETWEEN WING AND NO WING FOR LOCATION OF 0.75 RADIUS AND 0.1 CHORD, SUCTION SURFACE, $J=0.88, M_{\infty}=0.2$. TIP SPEED $=244$ $\mathrm{M} / \mathrm{SEC}(800 \mathrm{FT} / \mathrm{SEC})$. 


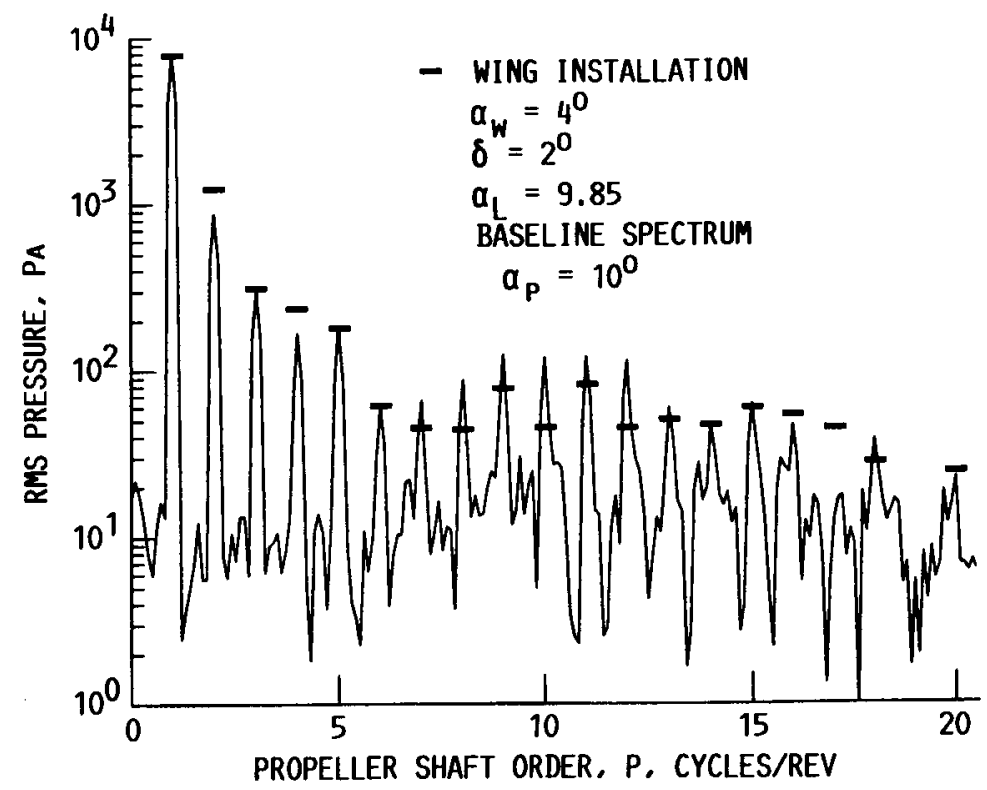

FIGURE 16. - SPECTRA COMPARISON BETWEEN WING AND NO WING FOR A LOCATION OF 0.75 RADIUS AND 0.1 CHORD. SUCTION SURFACE, $J=0.88, M_{\infty}=0.2$, TIP SPEED $=244 \mathrm{M} / \mathrm{SEC}(800 \mathrm{FT} / \mathrm{SEC})$. 


\begin{tabular}{|c|c|c|c|}
\hline \multicolumn{4}{|l|}{$\prod_{\substack{\text { National Aeronautics and } \\
\text { Space Administration }}}$} \\
\hline $\begin{array}{l}\text { 1. Report No. } \text { NASA TM-100200 } \\
\text { AIAA-87-2719 }\end{array}$ & 2. Government Accession No. & \multicolumn{2}{|c|}{ 3. Recipient's Catalog No. } \\
\hline 4. Title and Subtitle & & \multicolumn{2}{|l|}{ 5. Report Date } \\
\hline \multirow{2}{*}{\multicolumn{2}{|c|}{$\begin{array}{l}\text { Advanced Turboprop Wing Installation Effects } \\
\text { Measured by Unsteady Blade Pressure and Noise }\end{array}$}} & & \\
\hline & & \multicolumn{2}{|c|}{ 6. Performing Organization Code } \\
\hline \multirow{2}{*}{\multicolumn{2}{|c|}{$\begin{array}{l}\text { 7. Author(s) } \\
\text { Laurence J. Heidelberg and Richard P. Woodward }\end{array}$}} & \multicolumn{2}{|c|}{$\begin{array}{l}\text { 8. Performing Organization Report No. } \\
\text { E-3737 }\end{array}$} \\
\hline & & \multicolumn{2}{|l|}{$\begin{array}{l}\text { 10. Work Unit No. } \\
535-03\end{array}$} \\
\hline \multirow{2}{*}{\multicolumn{2}{|c|}{$\begin{array}{l}\text { 9. Performing Organization Name and Address } \\
\text { National Aeronautics and Space Administration } \\
\text { Lewis Research Center } \\
\text { Cleveland, Ohio } 44135-3191\end{array}$}} & \multicolumn{2}{|c|}{ 11. Contract or Grant No. } \\
\hline & & \multirow{2}{*}{\multicolumn{2}{|c|}{$\begin{array}{l}\text { 13. Type of Report and Period Covered } \\
\text { Technical Memorandum }\end{array}$}} \\
\hline \multicolumn{2}{|c|}{ 12. Sponsoring Agency Name and Address } & & \\
\hline \multicolumn{2}{|c|}{$\begin{array}{l}\text { National Aeronautics and Space Administration } \\
\text { Washington, D.C. 20546-0001 }\end{array}$} & \multicolumn{2}{|c|}{ 14. Sponsoring Agency Code } \\
\hline \multicolumn{4}{|c|}{$\begin{array}{l}\text { 15. Supplementary Notes } \\
\text { Prepared for the } 11 \text { th Aeroacoustics Conference sponsored by the American } \\
\text { Institute of Aeronautics and Astronautics, Sunnyvale, California, October } \\
19-21,1987 \text {. }\end{array}$} \\
\hline \multicolumn{4}{|c|}{$\begin{array}{l}\text { (0.2 Mach) in the NASA Lewis } 9 \text { - by } 15-\text { Ft Anechoic Wind Tunnel. Both unsteady blade surface pres- } \\
\text { sures and noise measurements were made for a tractor configuration with a propeller/straight wing } \\
\text { and propeller alone configurations. The angle between the wing chord and propeller axis (droop } \\
\text { angle) was varied along with the wing angle of attack to determine the effects on noise and unsteady } \\
\text { loading. A method was developed that uses unsteady blade pressure measurements to provide a quanti- } \\
\text { tative indication of propeller inflow conditions, at lease for a uniform (across the propeller disk) } \\
\text { inflow angle. The wing installation caused a nearly uniform upwash at the propeller inlet as evi- } \\
\text { denced by the domination of the pressure spectra by the first shaft order. This inflow angle } \\
\text { increased at a rate of almost } 150 \text { percent of that of the wing angle-of-attack for a propeller-wing } \\
\text { spacing of } 0.54 \text { wing chords at a constant droop angle. The flyover noise, as measured by the maxi- } \\
\text { mum blade passing frequency level, correlates closely with the propeller inflow angle ( } 0.6 \text { dB per } \\
\text { degree of inflow angle) for all droop angles and wing angles-of-attack tested, including the propel- } \\
\text { ler alone data. Large changes in the unsteady pressure responses on the suction surface of the blade } \\
\text { were observed as the advance ratio was varied. The presence of a leading edge vortex may explain } \\
\text { this behavior since changes in the location of this vortex would change with loading (advance ratio). }\end{array}$} \\
\hline $\begin{array}{l}\text { 17. Key Words (Suggested by Author(s)) } \\
\text { Turboprop noi se } \\
\text { Installation effects } \\
\text { Unsteady blade pressur } \\
\text { Unsteady pressure resp }\end{array}$ & & \multicolumn{2}{|c|}{$\begin{array}{l}\text { 18. Distribution Statement } \\
\text { Unclassified - Unlimited } \\
\text { Subject Category } 02\end{array}$} \\
\hline $\begin{array}{l}\text { 19. Security Classif. (of this report) } \\
\text { Unc las s if i ed }\end{array}$ & $\begin{array}{l}\text { Security Classif. (of this page) } \\
\text { Unclass if ied }\end{array}$ & $\begin{array}{c}\text { 21. No of pages } \\
22\end{array}$ & $\begin{array}{r}\text { 22. Price" } \\
\mathrm{A02} \\
\end{array}$ \\
\hline
\end{tabular}

